\title{
APOSENTADORIA - TEMPO DE SERVIÇO - CRITÉRIO DE PROPORCIONALIDADE
}

\begin{abstract}
Aposentadoria - Tempo de Serviço - Magistério - Critério da Proporcionalidade - Artigo 126, § $6^{\circ}$, da Constituição do Estado de São Paulo. $\mathrm{Na}$ diç̧ão da ilustrada maioria, em relação à qual guardo reservas, ao legislador constituinte estadual não ficou aberto espaço à disciplina da consideração do tempo de serviço de forma proporcional, considerada atividade geradora do direito à aposentadoria especial como é a dos professores. Precedente: Ação Direta de Inconstitucionalidade $n^{2}$ 755-6/SP, julgada pelo Pleno, tendo sido designado Redator para o acórdão o Ministro Maurício Corrêa, cuja veiculação ocorreu no Diário de Justiça de 6 de dezembro de 1996.
\end{abstract}

\section{SUPREMO TRIBUNAL FEDERAL}

Recurso Extraordinário n² 175.434

Recorrente: Estado de São Paulo

Recorrido: Aconcio Paulo Filardi

Relator: Sr. Ministro MARCO AURÉLIO

\section{ACÓRDĀO}

Vistos, relatados e discutidos estes autos, acordam os Ministros do Supremo Tribunal Federal, em segunda turma, na conformidade da ata do julgamento e das notas taquigráfi- cas, por unanimidade de votos, em conhecer do recurso e lhe dar provimento, nos termos do voto do Relator.

Brasília, 11 de dezembro de 1998.

NÉRI DA SILVEIRA - Presidente

MARCO AURÉLIO - Relator 


\section{RELATÓRIO}

O SENHOR MINISTRO MARCO AURÉLIO - O Tribunal de Justiça do Estado de São Paulo negou acolhida a pedido formulado em apelação, mantendo a sentença de folha 77 à 81 , que implicara a concessão de segurança, "para determinar a pronta expedição da certidāo de liquidação do tempo de serviço em nome do autor e sua ratificação, de forma que the seja possível requerer a aposentadoria" (folha 81).

Exsurgiram embargos declaratórios, rejeitados, a uma só voz, pelo Colegiado (folha 151 à 153).

No extraordinário de folha 155 à 166 , interposto com alegada base nas alíneas " $a$ " $e$ " $c$ " do permissivo constitucional, a Fazenda Estadual salienta, preliminarmente, que carece de legitimidade passiva, porquanto não foi a autoridade que indeferiu a certidão postulada. Noutro passo, insiste na inconstitucionalidade do $\S 6^{\circ}$ do artigo 126 da Carta Estadual, pois a aposentadoria especial dos professores pressupõe o efetivo exercício das funções pelo prazo assinalado, não havendo falar-se na contagem proporcional para fins "de redução dos lapsos temporais, constitucionalmente definidos para ensejar a inatividade do servidor" em outro cargo ou função, até porque apenas mediante lei complementar editada pela União podem-se estabelecer exceções à regra fixada na Lei Maior. Tem-se por vulnerados os artigos 40 , inciso III, alíena " $b$ " e $\S 12$, e $61, \S 12$, inciso II, alinea “a”, do Diploma Fundamental.

O Recorrido ofereceu as contra-razōes de folha 168 à 173, estando o procedimento atinente ao juízo primeiro de admissibilidade consubstanciado na peça de folha 183 à 185 .

Em 6 de maio de 1994, determinei o encaminhamento dos autos à Procuradoria Geral da República, que exarou o parecer de folha 191 à 192, no sentido do provimento do recurso.

É o relatório.

\section{VOTO}

O SENHOR MINISTRO MARCO AURÉ-
LIO (RELATOR) - Os pressupostos gerais de recorribilidade estão atendidos. $\mathrm{O}$ recurso veio subscrito por procurador do Estado, havendo sido observado o prazo em dobro para a respectiva interposição. Resta examinar o específico.

Sob o ângulo da legitimidade, o recurso padece da ausência de indispensável prequestionamento. O tema não foi objeto de debate e decisão prévios perante a Corte de origem, quer no acórdão proferido por força da apelação (folhas 131 e 132), quer no decorrente dos embargos declaratórios (folha 151 à 153). Por sinal, nos citados embargos, a Fazenda silenciou a respeito. Assim, no particular, inviável é o reconhecimento deste extraordinário.

Quanto ao tema de fundo, surge a propriedade do extraordinário, vez que a Corte de origem acabou por placitar, como constitucional, o $\$ 6^{\circ}$ do artigo 126 da Carta local:

$\S 6^{\circ} \mathrm{O}$ tempo de serviço prestado sob o regime de aposentadoria especial será computado da mesma forma, quando o servidor ocupar cargo de regime idêntico, ou pelo critério da proprocionalidade, quando se trate de regimes diversos.

Ao ser apreciada a Ação Direta de Inconstitucionalidade $\mathrm{n}^{2}$ 755-6/SP, mediante a qual foi atacado o preceito da Constituição do Estado de São Paulo que serviu de base ao julgamento procedido na Corte de origem artigo $126, \S 6^{\circ}$, sustentei a harmonia do preceito com a Carta da República. Na oportunidade, funcionando como Relator, tive oportunidade de ressaltar:

$E$ realmente improcede o vício de inconstitucionalidade. $O \& 1^{2}$ do artigo 40 da Carta de 1988 reserva à lei complementar a possibilidade de se ter exceções ao disposto no inciso III, alíneas " $a$ " $e$ " $c$ " do artigo 40 da Carta da República, sendo certo, ainda, sob o ângulo formal, que na alínea " $c$ " do inciso II do $\S l^{\varrho}$ do artigo 61 da Lei Maior prevê-se a iniciativa privativa do Presidente da República em se tratando de leis que disponham sobre servidores públicos da União e Territórios, seu regime jurídico, provimento de cargos, estabilidade e aposentadorias de ci- 
vis, reforma e transferência de militares para a reserva.

Ora, a atuação dos Estados visando à própria organizaçāo guarda estreita submissão aos princípios da Carta da República - artigo 25.

Diante de tais premissas, tenha-se presente a norma atacada:

" $\$ 6 "$ - O tempo de serviço prestado sob o regime de aposentadoria especial será computado da mesma forma, quando o servidor ocupar outro cargo de regime idêntico, ou pelo critério de proporcionalidade, quando se trate de regimes diversos."

Inegavelmente, enseja o preceito a junção de regimes distintos de inativação, ao prever o cômputo, embora de forma proporcional, de periodos a eles subordinados. À citada regra, após reflexão maior do que a feita quando pronunciei-me a respeito do pedido de concessão liminar, empresto alcance consentâneo com o Diploma Máximo. A alusão ao regime de aposentadoria especial faz-se tendo em vista o que neste se contém, ou seja, o texto da aliena " $d$ " do inciso III do artigo 40, segundo o qual é possível a aposentadoria voluntária aos trinta anos de efetivo exercício em fun-ções de magistério, se professor, $e$ vinte e cinco anos, se professora, com proventos integrais. Não tenho o dispositivo como a albergar contagem de tempo de serviço concernente à atividades consideradas penosas, insalubres ou perigosas, quando mister se faz a disciplina mediante a lei complementar prevista no $\$ 1^{\circ}$ do artigo 40 . Näo, a norma local diz respeito ao cômputo do tempo de serviço em que exercida função do magistério, para mim passivel de ser procedido administrativamente, mediante simples interpretação do artigo 40 da Constituição Federal. Ora, se o servidor público deixa de exercer essa função, tem o tempo respectivo contado para efeito de aposentadoria tal como definido na alínea " $b$ ", ou seja, assentada a necessidade de perfazer trinta anos, se professor, ou vinte e cinco anos, se professora.

Nâo se há de conferir à Lei Básica efeito que acabe por projetar na vala comum, ou seja, da aposentadoria aos trinta e cinco anos, se homem, e trinta, se mulher, situação concreta em que o beneficiário tenha traba-
Ihado em atividade para o qual é menor o tempo fixado. A meu ver, a circunstancia de não haver implementado, na função de magistério, o período total para ter jus à aposentadoria não implica a exclusão de tal tempo de modo proporcional. Em ultima análise, como exemplificado pela Procuradoria Geral da República, uma professora com quinze anos de serviço, prevalente a norma local e, para mim, interpretada a própria Carta da República, buscando-se dela retirar a maior eficácia possivel - caso haja deixado o exercício do magistério e passando à função comum no serviço público, poderia aposentarse, em face à equação quinze vinte e cinco avos, com proventos totais caso viesse a trabalhar por mais doze anos, perfazendo, assim, o total de vinte e sete anos de serviço. Ora, a Constituição Federal, no que contempla tempo de serviço de menor extensão, em se tratando de professor, importa no reconhecimento do desgate que o exercício da função acarreta e este não desaparece em face da impossibilidade de se retornar ao statu quo ante, quando o servidor, por isto ou por aquilo, ascende a uma função comum. A consideração proporcional do período decorre, sob a minha óptica, do objetivo a norma da alinea " $b$ " do inciso III do artigo 40 da Constituição Federal, da mesma forma pela qual, completado o período de vinte e cinco anos, se professora, ou trinta, se professor, o servidor poderia aposentar-se com proventos totais antes de implementados, no novo cargo, os tempos normais, ou seja, trinta ou trinta e cinco anos.

Diante deste enfoque e conferindo ao preceito da Carta do Estado de São Paulo interpretação consetânea com a Lei Básica da República, julgo improcedente o pedido formulado, declarando, assim, com essa interpretação, a constitucionalidade do $\S 6^{\circ}$ do artigo I26 da Constituição do Estado de São Paulo.

Entrementes, a ilustrada maioria formou convencimento em sentido contrário. Eis como ficou formalizada a tese prevalecente, redigindo o acórdão o Ministro Maurício Corrêa:

AÇÃO DIRETA DE INCONSTITUCIONALIDADE. CONTAGEM PROPORCIONAL 
DO TEMPO DE SERVIÇO PRESTADO SOB O REGIME DE APOSENTADORIA ESPECIAL E SOB REGIME DIVERSO. IMPUGNAÇÃO DO $§ 6^{\circ} D O A R T .126 D A$ CONSTITUIÇÃO DO ESTADO DE SÃO PAULO: "O TEMPO DE SERVICO PRESTADO SOB O REGIME E APOSENTADORIA ESPECIAL SERÁ COMPUTADO SOB O REGIME DE APOSENTADORIA ESPECIAL SERÁ COMPUTADO DA MESMA FORMA, QUANDO O SERVIDOR OCUPAR OUTRO CARGO DE REGIME IDÊNTICO, OU PELO CRITÉRIO DA PROPORCIONALIDADE, QUANDO SE TRATE DE REGIMES DIVERSOS."

1. O art. 40 , III, $b$, da Constituição Federal assegura o direito à aposentadoria especial " aos trinta anos de efetivo exercício nas funfões de magistério, se professor, e vinte $e$ cinco, se professora, com proventos integrais"; outras exceções podem ser previstas em lei complementar (CF, art. 40, $\$ I^{\circ}$ ), " no caso de exercício de atividades consideradas penosas, insalubres ou perigosas".

2. A expressão "efetivo exercício em funçōes de magistério" contém a exigência de que o direito à aposentadoria especial dos professores só se aperfeiçoa quando cumprido totalmente este especial requisito temporal no exercício das especificas funçōes de magistério, excluida qualquer outra.

3. Não é permitido ao constituinte estadual nem à lei complementar federal fundir normas que regem a contagem do tempo de serviço para aposentadorias sob regimes diferentes, contando proporcionalmente o tempo de serviço exercido em funções diversas.

4. Ação direta conhecida e julgada procedente, por maioria, para declarar a inconsti- tucionalidade do $\$ 6^{\circ}$ do art. 126 da Constituição do Estado de São Paulo, porque o art. 40 da Constituição Federal é de observância obrigatória por todos os níveis do Poder. Precedente: $A D J$ n $178-7 / R S$.

Diante de tal quadro, impõe-se o conhecimento e provimento parcial do recurso para restringir a concessāo da segurança à expedição da certidão do tempo de serviço do Impetrante, expungida a mesclagem dos sistemas, e, portanto, a contagem proporcional.

\section{EXTRATO DE ATA}

\section{Recurso Extraordinário n $175.434-6$}

Proced.: São Paulo

Relator: Min. Marco Aurélio

Recte.: Estado de São Paulo

Adv.: Paris Piedade Junior e outros

Recdo.: Aconcio Paulo Filardi

Adv.: Marcos Augusto Perez e outros

Decisão: Retirado de pauta por indicação do Relator. Plenário, 23.9.98.

Decisão: Por unanimidade, a Turma conheceu do recurso e the deu provimento, nos termos do voto do Relator. Ausente, justificadamente, neste julgamento, o Senhor Ministro Carlos Velloso. 2a Turma, 11.12.98.

Presidência do Senhor Ministro Néri da Silveira. Presentes à Sessão os Senhores Ministros Marco Aurélio, Maurício Corrêa e Nelson Jobim. Ausente, justificadamente, o Senhor Ministro Carlos Velloso.

Subprocurador-Geral da República, Dr. Mardem Costa Pinto.

Carlos Alberto Cantanhede, Coordenador 